\title{
6 Lead NEHB-SPORI
}

National Cancer Institute

\section{Source}

National Cancer Institute. 6 Lead NEHB-SPORI. NCI Thesaurus. Code C132355.

An electrocardiogram (ECG) lead configuration that is primarily used to record ECGs in non-human animals, and which uses six (6) electrodes to generate eight (8) ECG leads (ECG wave forms). The six electrode configuration includes the following: four (4) limb electrodes, which are placed analogous to an Einthoven configuration in humans, and two (2) chest electrodes. The eight (8) ECG leads recorded comprise three standard limb leads (leads I, II, and III), three aug mented leads (Leads aVr, aVF, and aVL), and two chest leads, which are generated using two unipolar chest leads, typically CV5RL [rV2] and CV6LL [V2] for canines, or MV1 and MV2 for primates. (CDISC) 